REFERENCE:

[1] Kawashiri, et al. J Rheumatol 2011;38(12):2517-21.

Acknowledgements: Study financed with funds from the Emilia-Romagna Region deriving from the "Alessandro Liberati" young researchers in the framework of the. Region-University research program 2013

Disclosure of Interest: None declared

DOI: 10.1136/annrheumdis-2018-eular.5102

\title{
AB0420 DRUG SURVIVAL ON CERTOLIZUMAB AND PREDICTORS THEREOF IN PATIENTS WITH RHEUMATOID ARTHRITIS, PSORIATIC ARTHRITIS, AND AXIAL-SPONDYLOARTHRITIS FROM THE APULIAN BIOPURE REGISTRY
}

A. Semeraro ${ }^{1}$, G. Carlino ${ }^{2}$, R. Bucci ${ }^{3}$, F. D'Onofrio ${ }^{4}$, P.C. Falappone ${ }^{5}$, S. Lopriore ${ }^{6}$, A. Marsico ${ }^{1}$, N. Maruotti ${ }^{7}$, D. Mazzotta ${ }^{5}$, M. Muratore ${ }^{8}$, L. Quarta $^{8}$, L. Santo ${ }^{9}$, C. Zuccaro ${ }^{5}$, F. lannone ${ }^{6} .{ }^{1}$ Rheumatology Unit, ASL Taranto; ${ }^{2}$ Rheumatology Service, ASL LE Casarano; ${ }^{3}$ Rheumatology Hospital Unit, Foggia; ${ }^{4}$ UOC Reumatologia Universitaria, University of Foggia; ${ }^{5}$ Rheumatology Outpatients, "A. Perrino" Hospital, Brindisi; ${ }^{6}$ DETO - Rheumatology Unit, University of Bari; ${ }^{7} \mathrm{UOC}$ Reumatologia Universitaria, University of, Foggia; ${ }^{8}$ O.U. of Rheumatology, "V. Fazzi" Hospital, Lecce; ${ }^{9}$ O.U. of Rheumatology, ASL Barletta, Italy

Background: In BIO.PU.RE. Registry are collected data from patients being treated with Biologics from rheumatologic centres in Apulia (Southern Italy).

Methods: We analysed longitudinal data of consecutive patients, affected with RA, PsA or axial-SpA starting a treatment with certolizumab (CTZ) in the time frame from 1st January 2011 to 30th June 2017. Demographic and disease related characteristics were collected at baseline and at last observation visit. Primary endpoint was the persistence on CTZ, and secondary endpoint was the search of baseline predictors of drug survival and clinical outcomes. Drug survival was evaluated by Kaplan-Meier life table analysis. Estimates hazard ratios (HRs, $95 \%$ confidence intervals $(\mathrm{Cl})$ ) of drug discontinuation or achievement of low-disease/remission in RA, and minimal disease activity (MDA) in PsA at last visit, adjusted for patient's demographics, disease characteristics and prior biologic treatments were computed by Cox-regression stepwise backward models.

Results: 345 patients were included in this analysis (table 1). Global median survival time $(95 \% \mathrm{Cl})$ was 30 [23-36] months. Drug survival rate was significantly higher in SpA $(63.9 \%, \mathrm{p}=0.009)$ than in RA $(54.0 \%)$ or PsA $(54.5 \%)$. Within each disease, naïve-CTZ patients showed higher survival rates than biologic-experienced patients in RA (63.4\% vs $45.7 \%, p=0.0001)$, but not in PsA $(59.1 \%$ vs $52.3 \%, p=0.60)$, or $\mathrm{SpA}(62.5 \%$ vs $64.4 \%, \mathrm{p}=0.94)$. In the whole cohort, the only negative predictor of drug discontinuation was the CTZ-naïve status (HR 0.62 , $95 \mathrm{Cl} 0.40-0.96, p=0.03$ ). This association was even stronger for RA (HR 0.45 , $95 \mathrm{Cl} 0.26-0.77, p=0.004)$. In SpA, patient's age at baseline was weakly correlated to CTZ stopping (HR 0.96, $95 \mathrm{Cl} 0.93-0.99, \mathrm{p}=0.02$ ), but no predictor of CTZ discontinuation was detected in PsA. No factor did correlate to the achievement of low disease/remission in RA, while co-medication with MTX was significantly associated to the achievement of MDA (HR 3.82, $95 \mathrm{Cl} 1.26-11.54, \mathrm{p}=0.01$ ) in PsA. Globally, the causes of discontinuation were: ineffectiveness ( $\mathrm{nr} 94,27.2 \%$ ), adverse event (nr. 40,11.6\%), pregnancy (nr.1, 0.3\%), remission (nr. 3, 0.9\%), others (nr.13, 3.8\%).

Abstract AB0420 - Table 1

\begin{tabular}{lcccc}
\hline & $\begin{array}{c}\text { All } \\
\text { (nr. }\end{array}$ & $\begin{array}{c}\text { RA } \\
\text { (nr. }\end{array}$ & $\begin{array}{c}\text { PsA } \\
(\mathbf{n r} .88)\end{array}$ & $\begin{array}{c}\text { Ax- } \\
\text { SpA } \\
(\mathbf{n r} .83)\end{array}$ \\
\hline Age (mean) & $\mathbf{3 4 5}$ & $\mathbf{1 7 2})$ & & 45.7 \\
& $46.9 \pm 11$ & $48.8 \pm 12$ & 44.4 & \pm 11 \\
Female & & & \pm 10 & $43.3 \%$ \\
BMI (mean) & $72.9 \%$ & $86.2 \%$ & $71.6 \%$ & $26.7 \pm 5$ \\
Dis Durat (mean) & $27.3 \pm 5$ & $26.4 \pm 4$ & $29.4 \pm 5$ & $9.2 \pm 9$ \\
Naive & $8.8 \pm 8$ & $8.7 \pm 8$ & $8.6 \pm 7$ & $28.9 \%$ \\
Prior biologics & $37.1 \%$ & $47.1 \%$ & $25.0 \%$ & $71.1 \%$ \\
Glucocorticoids & $62.9 \%$ & $52.9 \%$ & $75.0 \%$ & $41.0 \%$ \\
Methotrexate & $64.6 \%$ & $79.3 \%$ & $50.0 \%$ & $27.3 \%$ \\
Comorbidities & $60.3 \%$ & $73.0 \%$ & $45.5 \%$ & $65.1 \%$ \\
DAPSA (mean) & $62.3 \%$ & $58.0 \%$ & $68.2 \%$ & \\
& & & 22.8 & \\
DAS28 (mean) & & $4.8 \pm 1$ & & \\
Extra-articular & & & & $21.7 \%$ \\
HLA-B27 (nr.44) & & $72.4 \%$ & & $64.8 \%$ \\
RF/ACPA + & & & & \\
\hline
\end{tabular}

